www.jmscr.igmpublication.org

Impact Factor 3.79

Index Copernicus Value: 5.88

ISSN (e)-2347-176x ISSN (p) 2455-0450

crossref DOI:_http://dx.doi.org/10.18535/jmscr/v4i02.62

\title{
Variation of Leukocyte Count in Athletes Before and After Exercise
}

\section{$\underline{\text { (Research Article) }}$}

Authors

\section{Gunti Durga Devi ${ }^{1}$, V. Malleswaramma ${ }^{2}$, P Ravi Kumar ${ }^{3}$}

${ }^{1,3}$ Associate Professor, Department of Physiology, RIMS, Ongole - 523001, Andhra Pradesh, INDIA

${ }^{2}$ Professor \& HOD, Dept of Physiology, Guntur Medical College, Guntur - 522 004, Andhra Pradesh,

*Corresponding Author

\section{Dr Gunti Durga Devi, MD}

Associate Professor, Department of Physiology, Rajiv Gandhi Institute of Medical Sciences [RIMS],

Ongole, Prakasam District - 523001, Andhra Pradesh, INDIA

Email: drdevigunti@yahoo.com Phone (or Mobile) No.: +919985894282

\section{Abstract}

Aim: To evaluate the difference in leucocyte count before and after exercise in athletes.

Methods \& Materials: This study was conducted by selecting twenty healthy athletes within the age group of 18-24 years. They were exposed to regular running for atleast 3 years prior to this study. Procedure was explained to them. Before starting the procedure they were advised to take rest for 1 hour. As to start the procedure heart rate and blood pressure were checked and blood samples were taken to estimate the total leukocyte count and differential leukocyte count. After taking the sample the subjects were instructed to run for 20 minutes. After stopping the running again the blood samples were taken for same parameter. For estimation of total leukocyte count Turk's fluid was used and for differential leukocyte count the smear was stained with Leishman's stain.

Results: $P$ value of $<0.001$ was considered as statistically significant.

Conclusion: Leukocyte counts will increase after exercise in athletes.

Key words: Turk's fluid, Leishman's stain, Cytokines, Interleukins

\section{Introduction}

In multicellular organisms each individual cell function for the well being of the entire organism of the whole body functions for the benefit of each individual cell which is known as homeostatis, a term coined by W.B. Cannon. ${ }^{[1]}$
A stress such as the physical exercise produces destabilization of homeostatis. The compensatory mechanisms existing in the multicellular organisms like human body, battle with the stress induced effects and bring back the homeostatic state. In most instances, such compensatory 
mechanisms operate in a feedback systems, which are endocrine in nature.

The stressful condition of the human body as in dynamic exercise increases the leukocytes, the motile unites of the body's defense system.

Exercise or adrenal injection mobilizes the marginated granulocytes causing a temporary rise in WBC count.

Regular exercise increases resistance to infections such as the common cold. There is accumulating evidence that exercise is a life style that offers some protection against malignancy. It has become clear that moderate exercise stimulates the immune system and may be somewhat responsible for exercise related reduction in illness.

An effort has been made to evaluate the relationship between the different varieties of leukocytes and as such the immunological relationship between the pre exercise and post exercise levels in athletes. The total leukocyte count, neutrophil, lymphocyte, monocyte concentrations increase after exercise.

\section{Materials \& Methods}

The study was conducted on male subjects, with age ranging from 18-24 years who are non smokers and non alcoholic not suffering with any ailment, disease or infection for the last one month till the completion of study. Twenty subjects are selected for procedure.

Each of the individual was medically examined and their past medical history has been carefully evaluated with an aim to exclude those individuals with cardiac or pulmonary disease or hypertension or diabetes mellitus. Thus unhealthy subjects were excluded and only the normal healthy male adults are accepted for this study. All the subjects were free from any infections and are not taking any drugs.

The criteria for selection of athletes is based on the fact that they have been trained or exposed to regular running for at least 3-4 years prior to the present study.
Prior to the study each subject was informed in details of its objectives and the aim of the research protocols and the methods to be used. Their consent was taken. They were well educated and motivated so at to extend the best cooperation in various exercise protocol.

Experimental protocol:

Twenty four hours before the experiment commenced subjects were refrained from taking any type of exercise and they are also abstained from caffeine containing beverages for 24 hours prior to and during the exercise. No attempt was made to limit the food or the other liquid intake. Before the actual procedure is begun the individual is subjected to a preceding period of rest ranging from half hour to one hour.

As a measure of dynamic exercise the subjects were asked to run for 20 minutes.

When he is ready to participate in the exercise protocol, the resting heart rate and the blood pressure are recorded. The heart rate is recorded by counting the pulse rate by palpating the radial pulse. Then the blood pressure both systolic and diastolic is recorded by using sphygmomanometer and the stethoscope. These recordings are made while the subject is made to lie flat on the table.

Blood samples are taken for the estimation of the total leukocyte counts and the differential counts of the leukocytes by giving a prick to the tip of the ring finger much a lancet under sterile conditions. The total leukocyte count was done by staining with Turks fluid and examining under a compound microscope with the help of Improved Neubauer's counting chamber. The differential leukocyte count was done after staining the smear with Leishman's stain and examining with the help of oil emersion lens.

After making the initial recording of the above parameters at rest the subject is instructed to run for 20 minutes. After stopping the exercise the blood samples are collected for the same parameters.

The data was analysed and the $p$ value of $<0.001$ was considered as statistically significant. 


\section{Results}

In athletes at rest the mean total leukocyte count is $6.64 \pm 0.6745$, the mean neutrophil count is $54.56 \pm 2.7092$, the mean lymphocyte count is $30.92 \pm 1.8239$, the mean monocyte count is $6.04 \pm 0.6110$.

After exercise, the mean leukocyte count is $9.452 \pm 0.6564$, the mean neutrophil count is
$58.28 \pm 1.6713$, the mean lymphocyte count is $33.76 \pm 1.7387$ and the man monocyte count is $7.36 \pm 0.7571$.

So when a comparision is made between pre and post exercise levels the total leukocyte count and as well as neutrophil count, lymphocyte count, monocyte count will show increased levels after exercise.

\section{Tables}

Comparison of total leukocyte counts in athletes at rest and after exercise

\begin{tabular}{|l|l|l|l|l|l|l|l|}
\cline { 2 - 7 } \multicolumn{1}{c|}{} & \multicolumn{2}{|l|}{ Athletes at rest } & \multicolumn{4}{l|}{ Athletes after exercise } & \multicolumn{4}{l|}{ t } \\
\cline { 2 - 8 } \multicolumn{1}{c|}{} & Mean & SD & Mean & SD & t & P & $\% \downarrow \uparrow$ \\
\hline $\begin{array}{l}\text { Total Leukocyte } \\
\text { counts }\end{array}$ & 6.64 & 0.67 & 9.45 & 0.66 & 14.9373 & $<0.001$ & $42 \% \uparrow$ \\
\hline
\end{tabular}

Comparison of Neutrophil counts, Lymphocyte counts and Monocyte counts in athletes at rest and after exercise

\begin{tabular}{|l|l|l|l|l|l|l|l|}
\cline { 2 - 8 } \multicolumn{1}{c|}{} & \multicolumn{2}{c|}{ Athletes at rest } & \multicolumn{3}{l|}{ Athletes after exercise } & \multicolumn{3}{l|}{} \\
\cline { 2 - 8 } \multicolumn{1}{c|}{} & Mean & SD & Mean & SD & t & P & $\% \downarrow \uparrow$ \\
\hline Neutrophils & 54.56 & 2.7092 & 58.28 & 1.6713 & 5.8424 & $<0.001$ & $7 \% \uparrow$ \\
\hline Lymphocytes & 30.92 & 1.8239 & 33.76 & 1.7388 & 5.6344 & $<0.001$ & $9 \% \uparrow$ \\
\hline Monocytes & 6.04 & 0.611 & 7.36 & 0.7572 & 6.7832 & $<0.001$ & $22 \% \uparrow$ \\
\hline
\end{tabular}

\section{Discussion}

In our study there is an increase in total leukocyte count and also an increase in the neutrophils, lymphocytes and monocytes after exercise compared with the pre exercise level. ${ }^{[2,3,4]}$ Leukocytes play an important role in many clinical and physical stresses like surgery, trauma, sepsis and burns which induce as pattern of normal and immunological responses that have similarities to that of exercise. Exercise induces mobilization of most leukocytes causing leucocytosis. ${ }^{[5]}$

Exercise stimulates cytokine release. The haemopoietic growth factors are called cytokines. Cytokine whose amino acid sequence is known is called as interleukin (L). The haemopoietic growth factors are the proteins that act as the intercellular mediators and control the growth differentiation and function of blood cells. ${ }^{[6]}$
These growth factors originate from the macrophage endothelial cells, fibroblasts, and are present in tissue fluids and blood only in minute concentration.

Macrophages play a key role in controlling haemopoiesis through the secretion of cytokines ie I L-1 tumor necrosis factors etc.

The I L -1, I L -3, I L - 6 TNF thus act together in the protection of human body on exposure to stress such as physical exercise is brought about by the leukocytes through interleukins.

The increase in leukocyte number was due to increase in granulocytes especially neutrophils, as well as an increase in lymphocytes and monocytes. ${ }^{[7]}$ The increase of granulocytes after exercise is partly due to increased levels of cortisol. ${ }^{[8]}$

So exercise and catecholamine infusion increase blood leukocyte counts. This leukocytosis is 
caused by mobilization of the marginated pool of leukocytes and not bone marrow release of leukocytes. ${ }^{[9]}$ In addition to catecalamines, growth hormone and beta endorphins are increased during exercise causing leukocytosis. ${ }^{[10]}$

\section{Conclusion}

Regular moderate exercise causes leukocytosis including increase in granulocytes, monocytes and lymphocytes. The cellular immune system is highly influenced by muscular exercise which will protect the individuals from infections.

During childhood and adolescence, bouts of exercise serve as powerful stimuli to the immune system. The inter action between exercise stress and immune system provide unique opportunity to link basic and clinical physiology and to evaluate the role of underlying stress and immunophysiological mechanisms.

\section{References}

1. Text book of Physiology. Prof. GK PAL, $2^{\text {nd }}$ Edition 2001.

2. CHRISTER MALM, RODICA LENKEI \& BERTIL SJODIN. Effects of eccentric exercise on the immune system in men. $\mathrm{J}$ Appl Physiol 86: 461 - 468, Feb 1989.

3. BAJZ, KANTORSKI J, MAJEWSKA E, ZEMAN K, POKOCA L, FORNALCZK E, TCHORZEWSKI H, SOLOWSKA Z, LEWICKI R. Immunological status of competitive cyclists before and after the training season, Int J Sports Med. 1994 Aug; 15 (6) : 319 - 24.

4. CHISTENSEN RD, HILL HR. Exercise induced changes in the blood concentration of leukocyte populations in teenage athletes. Am J Pediatr Haematol Oncol 1987 Summer; 9 (2) : $140-2$.

5. MC CARTHY DA, DALE MM. The leucocytosis of exercise. A review and model. Sports Med. 1988 Dec; 6 (6) : 333 -63 .
6. DAN NEMET, MD, YOUNGMANOH, PHD, HO-SEONG KIM. MD, MARY ANN HILL, PHD \& DAN M. COOPER, MD. Effects of intense exercise on inflammatory cytokines and growth mediators in adolescent boys, Paediatrics Vol. 110. No. 4. October 2002, pp 681689.

7. ELIKIM A, WOLACH B, KODESH E, GAVRIELI R, RANDAY J, BEN-TOVIM T, YAROM Y, FALS B. Cellular and humoral immune response to exercise among gymnasts and untrained girls. Int $\mathbf{J}$ Sports Med. 1977 Apr; 18 (3) 208 - 12.

8. GABRIEL H, SCHWARZ L, BORN P, KINDERMANN W. Differential mobilization of leukocyte and lymphocyte subpopulations into the circulation during endurance exercise. Eur J Appl. Physiol Occup Physiol. 1992; 65 (6): 529-34.

9. STEPHAN R VAN EDDEN, JOHN GRANTON, JENNIFER M. HARDS, BARBAR A MOORE, AND JAMES C. HOGG. Expression of the cell adhesion molecules on leukocytes that de marginate during acute maximal exercise. J. Appl Physiol 86; 970 - 976, 1999.

10. BENTE KLARLUND PEDERSEN. The cellular immune system and muscular activity. The Center of Muscle Research, Department of Infectious Diseases, Denmark 